\title{
The UN Global Compact: moving toward sustainable development by adopting a new paradigm
}

\author{
M. B. Neace \\ Mercer University, USA
}

\begin{abstract}
This paper examines the UN initiative that encourages a new paradigm - a networking of scientists and their organizations, global businesses, NGOs and civil society organizations to implement its Global Compact's ten principles to move human activity toward sustainable development (SD). The ten principles encompass a holistic approach to SD focusing on contributions of global enterprises acting through government agencies, civil society, local organizations and communities, both horizontally and most importantly, vertically. Sustainability does not occur in a vacuum. SD can only happen when there is recognition of its holistic underpinning of all life, particularly human activity, in all of its dimensions and interconnectedness.

After a brief review of the UN Global Compact (UNGC), several holistic models are presented and discussed with focus on global business enterprises when implementing the new paradigm of competition - collaboration, transparency, interconnectedness - a holistic philosophy for commerce and community. The models suggest an approach that has potential to create win-win-win results; or as is known in the business community - triple bottom line (TBL). Applications of the TBL models can, and are, moving organizations and communities in which they operate toward SD.

Keywords: UN Global Compact, holistic SD, collaboration, interconnectedness, transparency, triple bottom line, beyond globalisation.
\end{abstract}

\section{Introduction}

This is a work in progress; not only in terms of UNGC's ten principles but also for my models used in this paper - where and how they are interconnected. Both are undergoing a co-evolutionary journey. Under the umbrella of 
'Globalization,' UNGC and models presented for discussion are evolving in a dynamic, complex world. As John Rennie Short [1] noted, globalization is bringing peoples closer apart and places further together. The UN has initiated numerous programs over the years addressing problems associated with poverty, underdevelopment, health, education, security, infrastructure - aimed at underdeveloped countries and poor of the world. These programs have had limited success for a variety of reasons including poor management, lack of coherence [2] and some hanky-panky internally. Prodigious amounts of energy and talent have been used in their creation. For example, the UN Millennium Development Goals, absorbed hundreds of hours (probably thousands) of leading scientists and policy makers from around the globe in its development, has a broad base of stakeholders including global businesses and has specific targets to reach in eight areas by 2015 , yet to date has shown little progress of reaching those goals [3].

The paper will focus on how businesses can make significant contributions to UNGC goals in spite of a rather shaky UN track record. Both are going through an interesting global transition period.

\section{UNGC}

The UNGC was inaugurated 26 July 2000. It is a clarion call for business leaders, large and small, global and local, to cooperate with UN agencies, labor groups and civil society to advance its ten principles in the areas of human rights, natural environment and anti-corruption. UN efforts in these areas, although lauded by most governments and NGOs, with successes here and there, but overall, results are less than satisfying. Some believe the battle is being lost [4]. As critiques have noted there is a need for integration, interconnectedness and collaboration across these often disparate programs. UNGC is expected to accomplish this goal using the creative, synergistic leadership of global companies [2]. Many global companies have initiated actions in these areas on their own, or as part of a part of a group professional effort, or in alliance with one or more NGOs. For examples, see: [5-8]. I will draw from these sites and others in discussing models that address the UN's holistic concerns regarding efforts to enlist businesses and their leaders to bring creativity and innovation to the resolution of these global problems. The UN has grappled with these issues for many years, with a variety of initiatives, most often through individual programs and NGOs with limited perspectives, such as the UN Environmental Program (UNEP) and labor issues through ILO. UNGC, through its Ten Principles is an effort to synergize the talent and resources of business leaders from a holistic perspective - all inclusive with business leadership as it's underpinning. To date over 2,500 organizations have signed on to adhere and promote the GCs ten principles. As originally drafted, there were nine principles. The tenth - regarding anti-corruption was added recently. Figure 1 outlines the ten principles.

As a condition of membership all participants agree to uphold and promote the ten principles, not only individually but also in partnership with other members and communities at large. Each member must submit a 
'Communication of Progress' (COP) every two years chronicling how they've upheld, made progress and promoted the principles. Failure to submit a COP can lead to an 'inactive' status. A benefit of being a GC member is having "rights" to use the UN symbol on products and communications. This has led to some abuses - greenwashing and 'bluewashing' - using the good image of the UN without accountability [9].

\section{The Ten Principles}

The first two principles are derived from the Universal Declaration of Human Rights:

1. Businesses should support and respect the protection of internationally proclaimed human rights within their sphere of influence; and

2. Make sure that they are not complicit in human rights abuses. The principles 3-6 are derived from the International Labour Organisation's Declaration on Fundamental Principles and Rights at Work:

3. Businesses should uphold the freedom of association and the effective recognition of the right to collective bargaining;

4. The elimination of all forms of forced and compulsory labour;

5. The effective abolition of child labour; and

6. Eliminate discrimination in respect of employment and occupation. The principles 7-9 are derived from the Rio Declaration on Environment and Development:

7. Businesses should support a precautionary approach to environmental challenges;

8. Undertake initiatives to promote greater environmental responsibility; and

9. Encourage the development and diffusion of environmentally friendly technologies;

The 10th and last principle is derived from the United Nations Convention against Corruption:

10. Businesses should work against all forms of corruption, including extortion and bribery.

Figure 1: The Ten Principles.

\section{The Transition}

The timing is appropriate. Business is going through a transition - redefining itself in a world of globalization where stakeholders and communities external to the supply chains are often clamorous for inclusiveness. Mission statements are broadening with adoption of TBL thinking: at minimum, more effective and efficient integration, collaboration and 'transparency' of value creation streams, 
particularly working on environmental and security issues. Now, issues mentioned above are on the table. This fits 'conveniently' with the concept of 'beyond globalization' $[10,11]$.

Global companies and Western governments (Northern Hemisphere) have 'pushed' free markets with the assistance of IMF, WTO and a host of economic alliances for the past four decades with some degree of success (See [12]). Yet concerns by both those on the inside and outside abound: poverty appears to be growing as does abuses to Mother Nature (For an interesting review of this situation, see [13]). Most transitions are works in progress with occasional steps backward.

The UNGC is an effort to adjudicate these many issues by enlisting the global corporate world - its leadership, innovative creativity and collaborative management skills. Corporate leadership has begun, in increasing numbers, transitioning toward broader visions for their organizations, including communities they operate in, including their impacts on the environment, including security (personal and resources), including concerns for poverty and the many issues it begets. In a book that traced this transition, Elkington [14] developed the précis - Triple Bottom Line. Triple Bottom Line (TBL) is a process of synchronous venturing for economic, environmental and social equity. For example, this would include synergistic integration of market/supply chain objectives, environmental concerns (especially as they increase costs), human rights and anti-corruption initiatives benefiting bottom lines of all stakeholders working collaboratively - delivering win-win-win outcomes (e.g., browse these web sites for TBL at work: [15-17]).

A major element in the transition to TBL is value transformation (Figure 2). Without a change in mind-set regarding doing one's job, TBL as an every-day process will not occur. Figure 2 is a value transformation paradigm that is crucial for TBL success. Value transformation allows for all to sit at 'common' table.

Value shifting to the proactive/creative level leads naturally to synergistic activities blending economics, ecology and social issues through combinations of good science, best management practices and the inclusion of local stakeholders [18-20]. The global business community plays a key role in this process: they have the knowledge, they have the skills, they understand risk (the precautionary principle), and they have the ability to create win-win-win situations - triple bottom lines. Other stakeholders at the local level play pivotal roles in the development and application of sustainable initiatives, including research, education, and formulation of regulatory policies and transforming these preparations into good science and best management practices. It's their lives too. Business acumen is required to bring order to disorder and to do it profitably. (See Figure 3.)

Building on Norgaard's [21] plea for pluralism, as does TBL thinking, it is essential for the global business community to recognize and respect that different groups and cultures have unique approaches to their view of the world, applying different assumptions and methodologies resulting in different models 


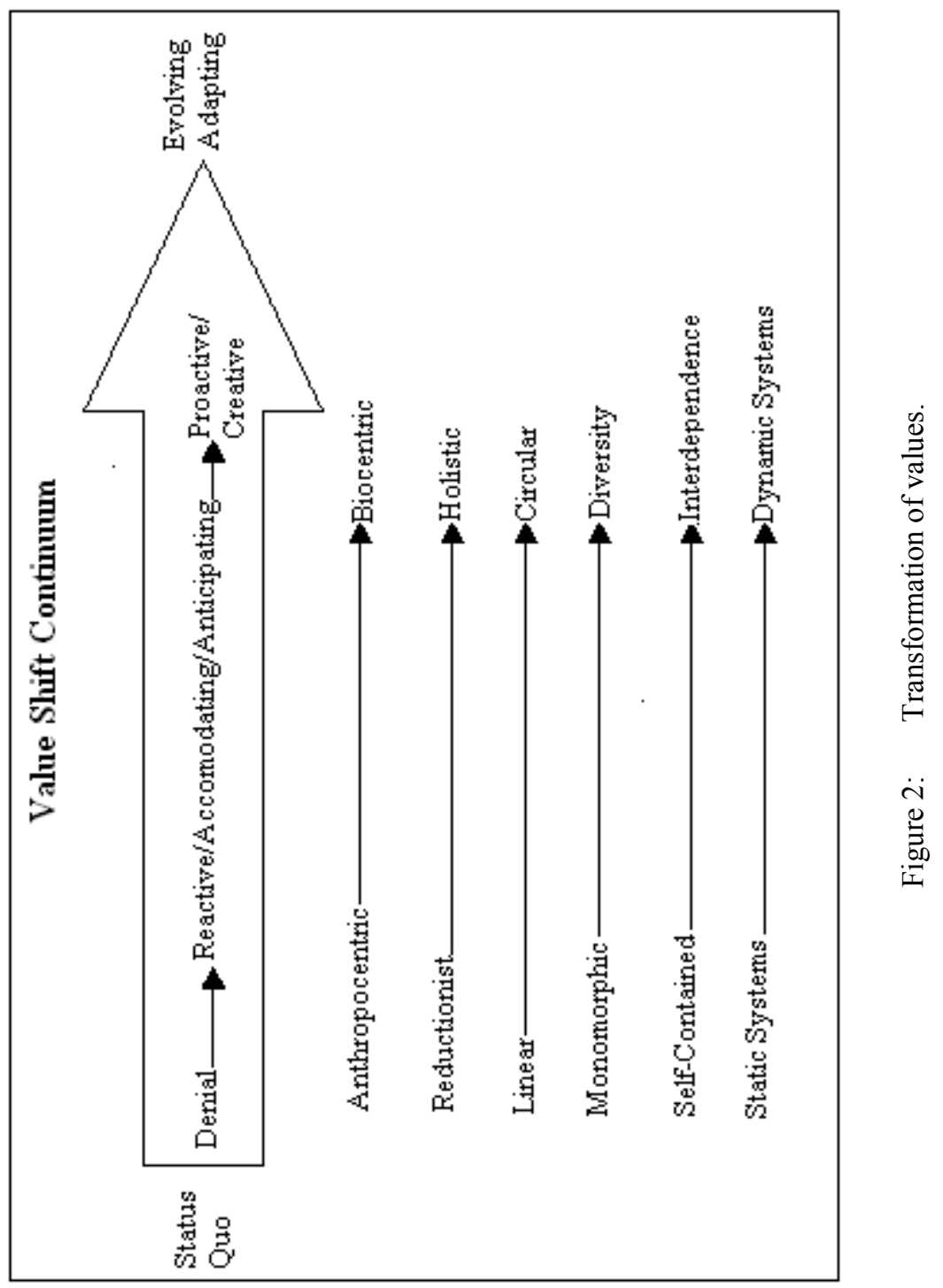




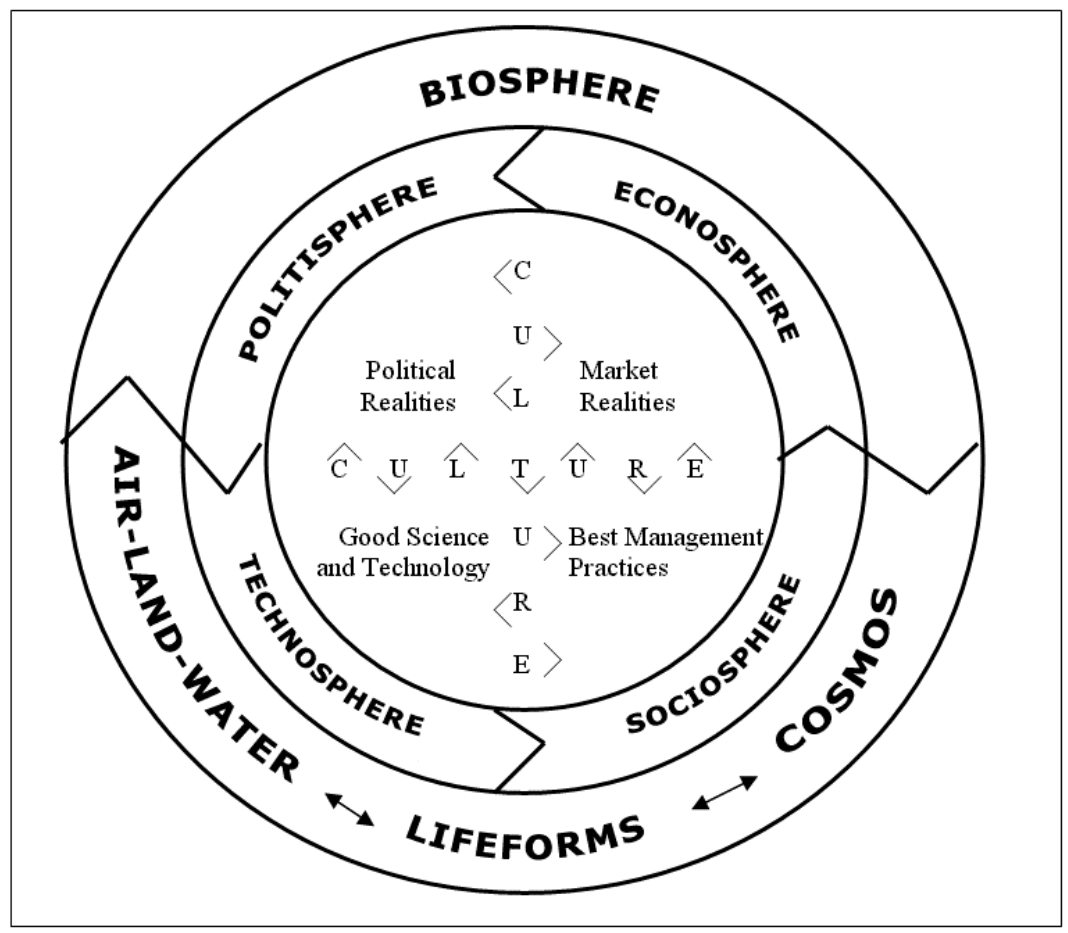

Figure 3: Integrated holistic TBL paradigm.

of the "same" phenomena. It is this very diversity and the synergy it creates that holds promise for progress toward a planetary system of sustainable development and some progress on UNGC's ten principles. There is no one unifying paradigm. Planet Earth is always evolving with many paradigmsinteracting, blending, competing, creating, dying - where Homo sapiens is an integral, and in fact, the dominant player in it's evolutionary path at this point in its history. Only in this way can we truly develop holistic, interconnected, dynamic paradigms necessary for movement toward TBL operationally [9, 22, 23]. The next section focuses primarily on sustainable development, which in its broad context is holistic and includes goals of the 'ten principles.'

\section{Making sustainability operational}

Limitations of present environmental policies and programs are well known; including bureaucratic ineptness and lack of will [24]; short term economicpolitical "remedies" at the sacrifice of long term biosphere reality $[20,25,26]$; application of reductionist paradigms when increasing evidence points to holistic dynamic general system [27-33]. Overcoming these issues is what the UN Global Compact is all about and why it requires expertise of global corporate leadership. 
A holistic perspective is required, including interconnectedness and local input. Norgaard [21], Rothschild [30] and Teilhard [33], among others, have developed holistic models demonstrating interconnections of man to his larger environment, the biosphere, and even the cosmos. Self organizing systems are ubiquitous in nature, as are economies of self organizing systems in which market structures spontaneously organize by demand for product/services and labor [34, 35]. Figure 3 expresses this integrated TBL holistic concept - a shift in values that recognizes continued development within each sector, but also the necessity for sharing and movement among the many bodies of knowledge - a transdisciplinary modus operandi, a recognition of interconnectedness and diverse cultures. Certainly no one expects to attain this level of maturity and harmony without disputation. Healthy debate and respect is necessary for real progress. In spite of our wrangles the process is under way, and evermore with global business enterprises playing a leadership role. We are not implying the battle is being won. To the contrary, even with a shifting in values and growing numbers of global enterprises taking positive actions, such as broadening their vision statements to include NGOs and local stakeholders, some authorities claim we are losing the battle [4].

\section{Operationalizing a TBL platform}

Figure 3 is a TBL platform. A paradigm that recognizes the necessity for networking internally and externally - information sharing, learning, feedback; and connectedness must be vertical as well as horizontal to be holistic and for sustainable development to have any opportunity of success [36]. Twenty-five years of "command and control" policies targeted at the most obvious and egregious environmental problems, by media, are complex and now only marginally productive [37]. Continued progress in alleviating biospheric problems due to man's intrusions and consumption is proving to be complex and difficult. Assuring a sustainable and humane future requires global business leadership.

Holistic and inter-vertical, new initiatives, such as the UN Global Compact are "forcing" creative strategic planning by global enterprises to the local level; e.g., community pollution prevention programs, local government partnering and business compliance assistance, developing social capital through civil society. Local stakeholders are directly involved and have the most to win or lose with the development and health of their immediate surroundings [38, 39].

Many observers of the present environmental dilemma believe a significant number of undesirable outcomes of a monomorphic elitist bureaucracy could have been avoided with local socio-cultural input and gradual withdrawal of central control [24, 38, 39, 40, 41]. Without input of local stakeholders, whether they be farmers, ranchers, small manufacturers, community leaders, global enterprises, or consumers, a sustainable strategy is impossible. No one is suggesting governments and their agencies abandon responsibility of serving their peoples. But a growing number of business leaders, professionals and scholars are suggesting gradual withdrawal of central control. In most well- 
educated communities with rising levels of human consciousness and awareness of the connectedness of all life forms [33] central control just doesn't work; for example, the collapse of the Russian empire. Randhir and Lee [41] see roles of central governments as external observers, suppliers of technical know-how, nurturers of mutual trust among multi-stakeholders and assisting development of well-structured incentive systems. Government intervention achieves very little in the absence of local efforts [24]. Global enterprises have a tremendous opportunity to lead, integrate and set examples. Today, the metrics strongly suggest it is profitable to do so.

Pushing environmental and social responsibility to local stakeholders, including local businesses using TBL strategies with their diverse cultures, is risky. Conceptually, this also mimics dynamic diversity of the biosphere. By their very nature freedom and diversity are unpredictable and uncertain. But that is the TBL's stratagem's very strength: open mindedness, broad mindedness, tolerance, continually evolving, continually collaborating and competing openly in the market place of ideas and beliefs $[22,29]$.

\section{Conclusions}

To approach a life-style that is sustainable, UNGC's ten principles plus global business leadership will have to expand their linear-reductionist orientations to encompass a holistic view of man, Earth, and even the cosmos. Are the global enterprises of the world ready to utilize these resources in their economic and strategic planning? Are global enterprises ready to embrace fellow local stakeholders - horizontally and vertically - all integral parts of Planet Earth and its biosphere? Are they ready to create triple bottom line platforms using their leadership to bring coherence and synergism to creating a win-win-win world?

The battle has just begun. Several respected scientific journalists claim that progress is modest at best and in several cases moving backwards [4]. For sustainability to move toward becoming a reality inter-vertical as well as interhorizontal general systems should be implemented as a matter of general course by global enterprises, global NGOs, local socio-culture communities. Capitalizing on self-interest, collaboration and creativity are essential, the very essence of UNGC. Global business organizations have opportunities as well as responsibilities to encourage this inclusiveness for the betterment of all, for creating triple bottom lines so all can achieve their potential in a safe, secure and sustainable world.

\section{References}

[1] Short, J. R., Global dimensions: space, place and the contemporary world, London: Reaktion Books, 2001.

[2] Ruggie, J. G., "The United Nations and globalization: patterns and limits of institutional adaptation," Global Governance, Vol. 9, No. 3, 301-321, 2003.

[3] United Nations - Millennium Goals, www.un.org/millenniumgoals 
[4] Speth, J.G., Red sky at morning: America and the crisis of the global environment, New Haven, CT: Yale University Press, 2004.

[5] World Business Council for Sustainable Development, www.wbcsd.org

[6] Sustainable Forest Initiative, www.sfiprogram.org

[7] The International Council of Chemical Associations, www.responsiblecare.org

[8] Cement Sustainability Initiative, www.wbcsdcement.org

[9] CorpWatch, www.corpwatch.org

[10] Henderson, H., Beyond globalisation, West Hartford, CT: Kumarian Press, 1999.

[11] Rosenau, J. N., Distance proximities: Dynamics beyond globalisation, Princeton, NJ: Princeton University Press, 2003.

[12] World Trade Organization, www.wto.org

[13] Robins, R. H., Global problems and the culture of capitalism, $3^{\text {rd }}$ ed., Boston: Allyn and Bacon, 2005.

[14] Elkington, J., Cannibals with forks: The triple bottom line of $21^{\text {st }}$ century business, Gabriola Island, BC, Canada: New Society Publishers, 1998.

[15] Toyota, www.toyota.com

[16] British Pump, www.bp.com

[17] GE Ecomagination, ge.ecomagination.com

[18] Royston, M. G., Pollution prevention pays, New York: Pergamon Press, 1979.

[19] Saunders, T. and L. McGovern, The bottom line of green is black: Strategies for creating profitable and environmentally sound business, San Francisco: Harper, 1994.

[20] Schmidheiny, S., Changing course: A global business perspective on development and the environment, Cambridge, MA: MIT Press, 1992.

[21] Norgaard, Richard B., "Environmental economics: An evolutionary and a pleas for pluralism," Journal of environmental economics and management, (December), 382-394, 1985.

[22] Vedeld, Paul O., "The environment and interdisciplinary ecological and neoclassical economical approaches to the use of natural resources," Ecological economics, Vol. 10, No.1, 1-13, 1994.

[23] Waldrop, M. M., Complexity: The emerging science at the edge of order and chaos. NY: TOUCHSTONE, 1992.

[24] Hess, K., Jr., Visions upon the land, Washington, D.C.: Island Press, 1992.

[25] Hawken, P., The ecology of commerce, New York: Harper Collins, 1993.

[26] Rees, W.E., Sustainable development and the biosphere, Chambersburg, PA: ANIMA Books, 1990.

[27] Burrows, B. C., A. J. Mayne, and P. Newberry, Into the $21^{\text {st }}$ Century, Twickenham, U.K.: Adamantine Press Limited, 1991.

[28] Daly, H.E., Steady-state economics, $2^{\text {nd }}$ ed. Washington, D.C.: Island Press, 1991.

[29] Lovelock, J., Gaia: A new look at life on earth, Oxford, UK: Oxford University Press, 1979. 
[30] Rothschild, M., Bionomics, New York: Henry Holt and Company, 1990.

[31] Stikker, A., The transformation factor, Rockport, MA: Element, Inc, 1992.

[32] Tarnas, R., The passion of the western mind, New York: Harmon Books, 1991.

[33] Teilhard, de Chardin, P., The phenomenon of man, New York: Harper, 1959.

[34] Arthur, W. B., "Complexity and the Economy," Science, Vol. 284, (2 April), 107-109, 1999.

[35] Prigogine, I., Order out of chaos, NY: Bantam Books, 1989.

[36] Lewin, R., Complexity: Life at the edge of chaos, Chicago: University of Chicago Press, 1992.

[37] Norgaard, R.B., Development betrayed: The end of progress and a coevolutionary revisioning of the future, New York: Routledge, 1994.

[38] deGraaf, H. J., C. J. M. Musters and W. J. TerKeurs, "Sustainable development: Looking for new strategies," Ecological economics, Vol. 16, No. 3, 205-216, 1996.

[39] Enama, M. T., "Culture: The missing nexus in ecological economics perspectives,” Ecological economics, Vol. X, No. 2, 93-95, 1994.

[40] Neace, M. B., "Holistic sustainability: Local culture and global business - a unique opportunity," in Management of natural resources, sustainable development and ecological hazards, eds. Brebbia, Conti \& Tiezzi, Southampton, UK: WIT Press, 3-12, 2005.

[41] Randhir, T. O. and J. G. Lee, "Managing local commons in developing economics: An institutional approach," Ecological economics, Vol. 16, No. 1, 1-12, 1996. 